\title{
André Brochu écrivain, sous la direction de Micheline Cambron, Laurent Mailhot
}

\section{Simona Rossi}

\section{(2) OpenEdition}

1 Journals

\section{Edizione digitale}

URL: http://journals.openedition.org/studifrancesi/9363

DOI: 10.4000/studifrancesi.9363

ISSN: 2421-5856

\section{Editore}

Rosenberg \& Sellier

\section{Edizione cartacea}

Data di pubblicazione: 1 juin 2008

Paginazione: 233

ISSN: 0039-2944

\section{Notizia bibliografica digitale}

Simona Rossi, «André Brochu écrivain, sous la direction de Micheline Cambron, Laurent Mailhot», Studi Francesi [Online], 154 (LII | I) | 2008, online dal 30 novembre 2015, consultato il 12 janvier 2021. URL: http://journals.openedition.org/studifrancesi/9363 ; DOI: https://doi.org/10.4000/studifrancesi.9363

Questo documento è stato generato automaticamente il 12 janvier 2021.

\section{(c) (i) (9)}

Studi Francesi è distribuita con Licenza Creative Commons Attribuzione - Non commerciale - Non opere derivate 4.0 Internazionale. 


\title{
André Brochu écrivain, sous la direction de Micheline Cambron, Laurent Mailhot
}

\author{
Simona Rossi
}

\section{NOTIZIA}

André Brochu écrivain, sous la direction de Micheline CAMBRON, Laurent MAILHOT, Montréal, Hurtubise, 2006, pp. 223.

1 Il volume curato da Micheline Cambron e Laurent Mailhot costituisce la prima lettura globale dell'opera di André Brochu, cronista, critico, saggista, poeta e romanziere del nostro tempo. Gli scritti di Brochu, come emerge dall'analisi dei diversi studiosi che hanno collaborato alla miscellanea, sono caratterizzati dalla scelta di tematiche di grande attualità: dalla ormai proverbiale polemica linguistica all'invenzione verbale, dall'avvento del 'nazionalismo' moderno al riconoscimento della dignità dell'essaifiction.

2 Il volume, costituito da tre parti di uguale interesse: «Accès, situations»; «Croix, crû, croâ, chemins de la liberté»; «L'erre du poème», beneficia della collaborazione di critici e scrittori molto noti, tra i quali menzioniamo Jacques Brault, Renald Bérubé, Lucie Robert, François Ricard, Jacques Allard, Liana Nissim e Gilles Marcotte. Gli argomenti trattati sono i più svariati: $i$ passi precoci di Brochu in ambito letterario e la sua sete di cultura, la sua personalità ironica e moderna di professore fuori dagli schemi, la sua grande ammirazione per Sartre, Memmi, Barthes, il suo inappagabile desiderio di rispondere ai grandi interrogativi sull'essenza della letteratura, sulla sua esistenza e sul motivo per cui si scrive. Ma è soprattutto la sua facilità di scrittura che viene elogiata, il suo amore per la parola, quasi un essere vivente che viene lasciato esistere, errare, parlare, scorrere. «Je veux qu'on m'écrive», afferma con decisione Brochu, «je veux que 
les mots coulent de moi comme d'un autre» (pp. 77-78), tanto che alcuni critici definiscono la sua scrittura «une écriture-sonde, une écriture-recherche» (p. 77).

3 Lirica e mordente al tempo stesso, l'opera di André Brochu appare sotto una luce nuova in questo testo, che non vuole essere esaustivo, ma semplicemente dare un'idea - e ci riesce alla perfezione - del pregio di un autore che, ancora vivente, rappresenta già un tassello importante della letteratura quebecchese. 